\title{
Evaluation of leaf rust resistance and characteristics of Korean wheats
}

\author{
Minseo Kim ${ }^{1} \cdot$ Aro Lee $^{1} \cdot$ Hai An Truong ${ }^{1} \cdot$ Chon-Sik Kang $^{2} \cdot$ Changhyun Choi $^{2}$ \\ - Namhyun Chung ${ }^{1} \cdot$ Hojoung Lee ${ }^{1}$ Byung Cheon Lee ${ }^{1}$ (D)
}

Received: 31 July 2019 / Accepted: 26 August 2019 / Published Online: 30 September 2019

(C) The Korean Society for Applied Biological Chemistry 2019

\begin{abstract}
Leaf rust is the most widespread and destructive fungal disease, and outbreaks have always caused considerable losses in wheat yields. Thus, worldwide increases in wheat production depend on the development of leaf rust-resistant wheat varieties. In this study, we evaluated the resistance of forty Korean wheat cultivars to leaf rust at the seedling stage. Only two Korean wheats, $\mathrm{Ol}$ and Jonong, were resistant to leaf rust, whereas the remaining thirty-eight Korean wheats were susceptible to leaf rust. The $\mathrm{Ol}$ and Jonong varieties presented larger dry seed weights and higher antioxidant activity in response to leaf rust than the susceptible wheat varieties. No differences in $\beta$-1,3-glucanase activity or chlorophyll content between resistant and susceptible wheat varieties were observed. Overall, these results are important for the development of wheat varieties that are highly resistant to leaf rust and to understand the underlying mechanisms that confer leaf rust resistance.
\end{abstract}

Keywords Antioxidant capacity $\cdot \beta$-1,3-glucanase $\cdot$ Dry seed weight $\cdot$ Korean wheat $\cdot$ Leaf rust resistance $\cdot$ Puccinia triticina

\section{Introduction}

Wheat accounts for $19 \%$ of the total production of major cereal crops worldwide and its consumption is on the rise [1]. To ensure

Byung Cheon Lee $(\bowtie)$

E-mail: cheonii@korea.ac.kr

${ }^{1}$ College of Life Sciences and Biotechnology, Korea University, Seoul 02841, Republic of Korea

${ }^{2}$ Wheat Research Team, National Institute of Crop Science, RDA, Wanju, 55365, Republic of Korea

This is an Open Access article distributed under the terms of the Creative Commons Attribution Non-Commercial License (http://creativecommons. org/licenses/by-nc/3.0/) which permits unrestricted non-commercial use, distribution, and reproduction in any medium, provided the original work is properly cited. a sustainable future for humanity, wheat production yields must thus be increased. Wheat fungal diseases result in significant wheat yield losses. In particular, wheat leaf rust (Puccinia triticina) constitutes a major impediment to wheat production. Leaf rust disseminates rapidly and may produce catastrophic effects under optimal conditions [2]. It can be blown by winds and travel long distances, will end their crops within weeks of infection if they are not treated on time. There are various strategies to control wheat leaf rust, including the use of chemicals, biological controls, molecular markers, or the promotion of host resistance. The establishment of genetic resistance to leaf rust is the most studied and preferred method to prevent wheat yield loss. Currently, more than eighty leaf rust resistance $(L r)$ genes have been identified from diverse wheat varieties [3]. However, most $L r$ genes are not effective in conferring resistance to current races of leaf rust. Moreover, leaf rust has variable virulence and readily overcomes resistance through mutation [4]. Accordingly, new sources of resistance to leaf rust must be continually created and deployed. In this study, we evaluated forty Korean wheat cultivars for leaf rust resistance and characterized their distinct degrees of resistance and susceptibility. This study will help secure leaf rustresistant wheat resources while expanding the foundation for studying the mechanisms of leaf rust resistance.

\section{Materials and Methods}

\section{Plant Materials}

Forty Korean wheat cultivars (Triticum aestivum L.) were used in this study [5]. Leaf rust resistance was evaluated using the first leaves of 14-day-old seedlings. Cultivar seeds were sterilized with $5 \% \mathrm{NaOCl}$ for $7 \mathrm{~min}$ and washed five times with distilled water. The seeds were then stored at $4{ }^{\circ} \mathrm{C}$ for germination. After 3 days incubation, the seeds were sown in autoclaved soil. The seedlings were installed in a greenhouse and grown at $25^{\circ} \mathrm{C}$ for 14 days under daylight conditions. The average of 50-dry seed weight of selected wheat cultivars was determined with three replicates randomly. 


\section{Leaf rust inoculation}

The $P$. triticina strain was provided by the Korea Research Institute of Chemical Technology. The inoculum was prepared by diluting the uredospores of $P$. triticina in distilled water containing 120 il/L of Tween 20 (DAEJUNG, Siheung, Korea) [6]. The 14day-old seedling leaves were sprayed evenly with inoculum using an airbrush and incubated under dark conditions at $100 \%$ relative humidity for $24 \mathrm{~h}$ at $20{ }^{\circ} \mathrm{C}$. The phenotypic infection type and seedling response ( $0-4$ scale) were evaluated 10 days post-inoculation. The phenotypic performance of the cultivars varied from 0 to 4 : where, 0 indicated no visible symptoms; 0 ; indicated hypersensitive flecks; 1 indicated minute uredinia surrounded by mostly necrotic tissue; 2 indicated small- to medium-sized uredinia surrounded by chlorotic and/or necrotic tissue; 3 indicated large uredinia, without surrounding chlorosis; and 4 indicated large uredinia, without chlorosis or necrosis.

\section{Chlorophyll Assay}

Based on the evaluation of leaf rust resistance, four kinds of wheat which showed the most resistant (Keumkang, Jokyung) and susceptible (Ol, Jonong) to leaf rust were used in the future characteristics experiments. A total of $50 \mathrm{mg}$ of leaf material was collected from the first leaves of the 14-day-old seedlings. The leaf material was ground with a mortar and pestle in liquid nitrogen. Acetone $(80 \%)$ was used to extract the chlorophyll from the samples. Chlorophyll extraction was performed overnight under dark conditions at $4{ }^{\circ} \mathrm{C}$. The concentrations of chlorophyll $\mathrm{a}$, chlorophyll $\mathrm{b}$, and total chlorophyll were measured using a SpectraMax M2 spectrophotometer at 663 and $645 \mathrm{~nm}$ (Molecular devices, San Jose, CA, USA) [7,8] and calculated using the following equations.

$$
\begin{aligned}
& \text { Chlorophyll } \mathrm{a}=(12.7 \text { A663-2.69 A645) V/1000 W } \\
& \text { Chlorophyll } \mathrm{b}=(12.7 \text { A663-2.69 A645) V/1000 W } \\
& \text { Total Chlorophyll }(\mathrm{a}+\mathrm{b})=(12.7 \text { A663-2.69 A645) V/1000 W }
\end{aligned}
$$

In the equations, $\mathrm{V}$ is the extract volume $(\mathrm{mL})$ and $\mathrm{W}$ is fresh leaf weight $(\mathrm{g})$. The blank consisted of $80 \%$ acetone.

\section{$\beta-1,3-G l u c a n a s e$ Assay}

The first leaves from 14-day-old selected cultivars were sampled at 0,12 , and $24 \mathrm{~h}$ after leaf rust inoculation. A protein crude extraction was performed by grinding the first leaves in Pro-prep protein extraction solution (iNtRON, KOREA) using $700 \mu \mathrm{L}$ of buffer per $500 \mathrm{mg}$ leaf. The activity of $\beta$-1,3-glucanase was measured using 1\% laminarin (Sigma-Aldrich, USA) as a substrate. The reaction mixture, which contained $40 \mu \mathrm{L} 1 \%(\mathrm{w} / \mathrm{v})$ laminarin (in $0.2 \mathrm{M}$ phosphate buffer, $\mathrm{pH} 6.5$ ) and $20 \mu \mathrm{L}$ of crude enzyme solution, was incubated for $1 \mathrm{~h}$ at $37^{\circ} \mathrm{C}$. Subsequently, $40 \mu \mathrm{L} 1 \% \mathrm{NaOH}$ solution was added and the mixture was boiled for $5 \mathrm{~min}$ to terminate the reaction. One percent DNS $(3,5-$ dinitrosalicylic acid) reagent and supernatant mixed in a 1:1 ratio were boiled for $5 \mathrm{~min}$. After cooling, the color that developed was measured using a SpectraMax M2 spectrophotometer at $540 \mathrm{~nm}$ (Molecular devices, San Jose, CA, USA)[9-11]. The activity of $\beta$ 1,3-glucanase was calculated from the standard curve using glucose.

\section{DPPH (2,2-Diphenyl-1-picrylhydrazyl) Assay}

Antioxidants with weak A-H bonding will react with stable free radical 2,2-diphenyl-1-picrylhydrazyl (DPPH; Sigma-Aldrich), leading to discoloration of the molecule [12-14]. The 14-day-old seedlings were exposed to leaf rust stress for 0,12 , and $24 \mathrm{~h}$ under dark conditions. Leaf samples $(0.05 \mathrm{~g})$ were collected from three seedlings. Three replicates were included for each treatment. The samples were ground in liquid nitrogen and incubated using $400 \mu \mathrm{L}$ of $\mathrm{MeOH}(1 \% \mathrm{HCl})$ overnight under dark conditions at 4 ${ }^{\circ} \mathrm{C}$. The supernatant was collected by adding $400 \mu \mathrm{L}$ of distilled water and $400 \mu \mathrm{L}$ of chloroform at a 1:1 ratio before centrifuging at $3000 \mathrm{rpm}$ for $2 \mathrm{~min}$. A total of $300 \mu \mathrm{L}$ supernatant was dried overnight in a vacuum evaporator at $20^{\circ} \mathrm{C}$. The pellet was resuspended in $600 \mu \mathrm{L}$ of $\mathrm{MeOH}$ and centrifuged at $3000 \mathrm{rpm}$ for $2 \mathrm{~min}$. The $400 \mu \mathrm{L}$ supernatant was collected by adding equal amounts of $500 \mu \mathrm{M}$ DPPH. The reaction was completed in the dark at $25^{\circ} \mathrm{C}$ for $30 \mathrm{~min}$. The absorbance of DPPH was measured using a SpectraMax M2 spectrophotometer at $517 \mathrm{~nm}$ (Molecular devices, San Jose, CA, USA).

\section{Results and Discussion}

\section{Leaf rust resistance of forty Korean wheat cultivars}

Most of the Korean wheat cultivars were susceptible to leaf rust. Thirty-eight wheat cultivars were classified as having a phenotypic performance of either 2 or 3 against leaf rust infection. Only two cultivars, $\mathrm{Ol}$ and Jonong, were classified as having a phenotypic performance of 1 against leaf rust infection (Table 1 and Fig. 1). Most of the Korean wheat cultivars were relatively sensitive to leaf rust infection, and, consequently, it is important to develop a domestic wheat variety resistant to leaf rust.

\section{Dry seed weight and chlorophyll content of resistant and susceptible wheat cultivars}

Based on phenotypic evaluation of leaf rust resistance, ten Korean wheat cultivars, including $\mathrm{Ol}$ and Jonong, were examined for dry seed weight. The weight of fifty dry seeds from each of the ten Korean wheat cultivars were averaged and compared. The average seed weight of the two resistant wheat cultivars, $\mathrm{Ol}$ and Jonong, was much larger than the average seed weight of the susceptible wheat cultivars except for Jokyung wheat (Fig. 2). This suggests that seed weight might be associated with leaf rust resistance.

We compared the chlorophyll a, chlorophyll b, and total chlorophyll content of the leaves from 14-day-old seedlings of two susceptible wheat cultivars, Keumkang and Jokyung, and the 
Table 1. Phenotypic performance evaluation of the forty Korean wheat cultivars at the seedling stage to leaf rust infection

\begin{tabular}{|c|c|c|c|c|c|}
\hline Accession name & Phenotypic reaction* & Wheat type & Accession name & Phenotypic reaction* & Wheat type \\
\hline $\mathrm{Ol}$ & 1 & Red wheat & Jonong & 1 & Red wheat \\
\hline Geuru & 3 & Red wheat & Jokyung & 3 & Hard white wheat \\
\hline Dahong & 3 & Red wheat & Younbaeck & 2 & White wheat \\
\hline Chung-kye & 3 & Red wheat & Shinmichal No.1 & 2 & Red waxy wheat \\
\hline Eunpa & 2 & Red wheat & Dabun & 3 & Red wheat \\
\hline Tapdong & 2 & Red wheat & Baekjoong & 2 & Soft white wheat \\
\hline Namhae & 3 & Red wheat & Jeokjoong & 3 & Red wheat \\
\hline Uri & 2 & Soft red wheat & Sukang & 3 & Red wheat \\
\hline Olgeru & 2 & Soft red wheat & Hanbaek & 3 & White wheat \\
\hline Alchan & 3 & Soft red wheat & Suan & 3 & Red wheat \\
\hline Gobun & 3 & Soft red wheat & Dajung & 3 & Red wheat \\
\hline KeumKang & 3 & Hard white wheat & Goso & 3 & Soft red wheat \\
\hline Seodun & 2 & Soft Red wheat & Joa & 3 & Red wheat \\
\hline Saeol & 3 & Red wheat & HoJoong & 2 & Red wheat \\
\hline Jinpum & 3 & Red wheat & Baekchal & 3 & White wheat \\
\hline Milseoung & 2 & Hard red wheat & Jojoong & 3 & Red wheat \\
\hline Jo-eun & 2 & Red wheat & Baek-kang & 2 & White wheat \\
\hline Anbaek & 3 & Red wheat & SaeKeumKang & 3 & Red wheat \\
\hline Jopum & 3 & Hard red wheat & Taejoong & 2 & Red wheat \\
\hline Shinmichal & 3 & Red wheat & Johan & 2 & Red wheat \\
\hline
\end{tabular}

*; Phenotypic performance after leaf rust infection: $0=$ no visible symptoms; 0 ; $=$ hypersensitive flecks; $1=$ minute uredinia surrounded by mainly necrotic tissue; 2 = small- to medium sized uredinia surrounded by chlorotic and/or necrotic tissue; $3=$ large uredinia, without surrounding chlorosis; and $4=$ large uredinia, without chlorosis or necrosis

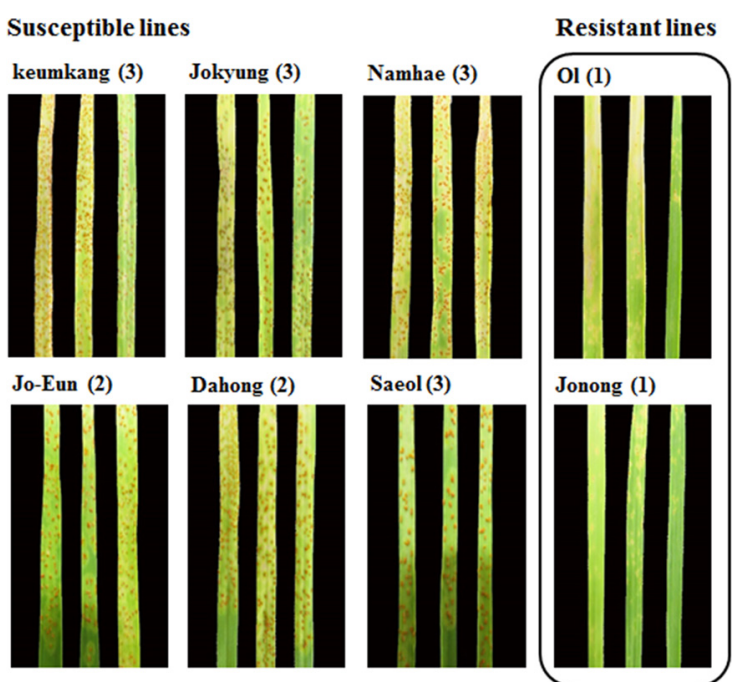

Fig. 1 Leaf rust-susceptible and leaf rust-resistant Korean wheat varieties. The type of leaf rust infection is shown according the phenotypic performance scale for susceptible and resistant Korean wheat varieties. The phenotypic performance of the cultivars varied from 0 to 4 were showed in the images

two resistant wheat cultivars, Ol and Jonong. No difference in chlorophyll content between the susceptible and the resistant cultivars was observed (Fig. 3). Overall, the leaf rust-resistant
Korean wheat cultivars presented relatively large seed weights compared to the leaf rust-susceptible wheat cultivars. However, chlorophyll content was similar between leaf rust-susceptible and leaf rust-resistant Korean wheat cultivars. Therefore, it is important for future studies to evaluate the underlying mechanisms responsible for seed weight variation, which may be associated with leaf rust resistance.

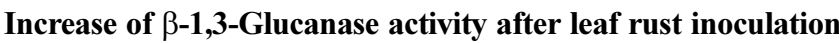
Give that $\beta$-1,3-glucanase breaks down the $\beta$-1,3-glucan that forms in the cell walls of fungal pathogens and thus contributes to the protection of plants from fungal infection $[15,16]$, the specific activity of $\beta-1,3$-glucanase was measured in this study. As expected, the specific activity of $\beta-1,3$-glucanase in all wheat cultivars tended to increase from 0 to $24 \mathrm{~h}$ after leaf rust inoculation (Fig. 4). However, no difference in $\beta$-1,3-glucanase activity between leaf rust-susceptible and leaf rust-resistant wheat cultivars was found. This suggest that that although $\beta-1,3-$ glucanase activity increased after leaf rust inoculation, it is not a determining factor for leaf rust resistance in Korean wheat cultivars.

\section{DPPH Assay for Antioxidant Activity Analysis}

Leaf rust induced the host oxidative stress in the resistance to invasive fungal disease. The change of antioxidant activity after 
(A)
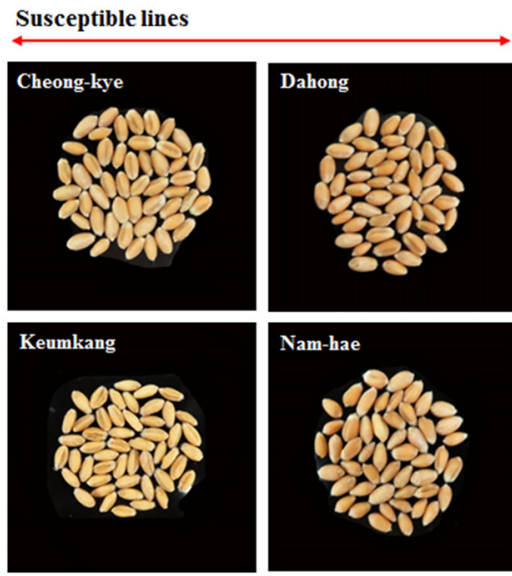

Resistant lines
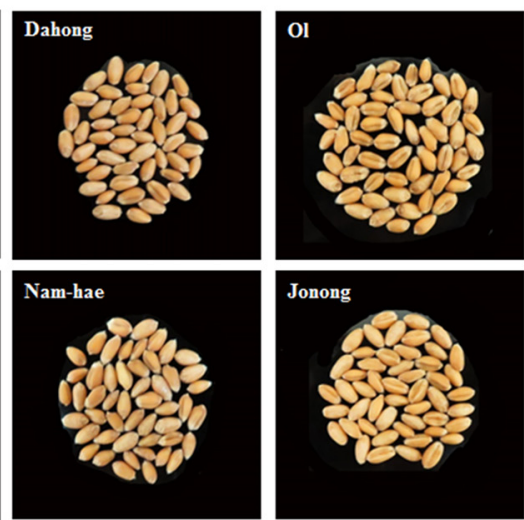

(B)

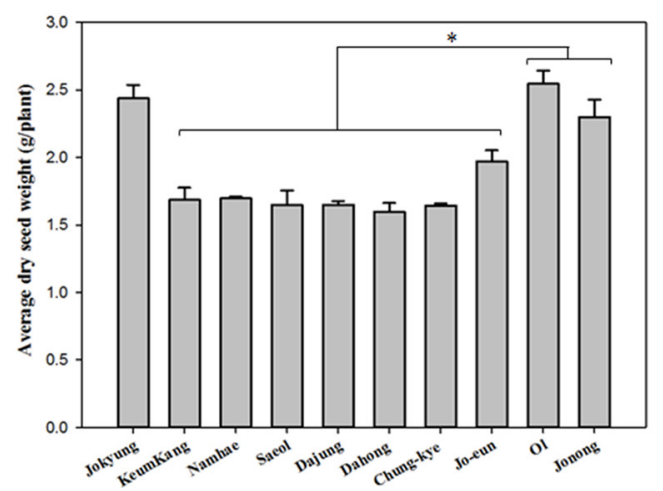

Fig. 2 Seed size and dry weight of Korean wheats. Comparison of (A) seed size and (B) average dry seed weight of susceptible and resistant Korean wheat varieties. For average dry seed weight, a total 50 seeds from each wheat cultivar were used $(* p<0.05$, Student's $t$-test)

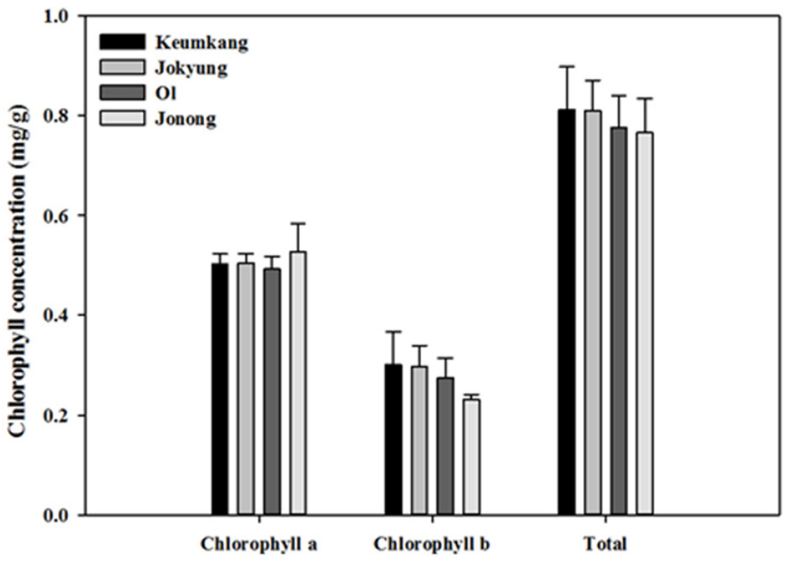

Fig. 3 Chlorophyll content of Korean wheat varieties. Comparison of chlorophyll content in two susceptible (Keumkang, Jokyung) and two resistant (O1, Jonong) Korean wheat varieties. Chlorophyll a, chlorophyll $\mathrm{b}$, and total chlorophyll content were analyzed $(* p<0.05, * * p<0.01$, Student's $t$-test).

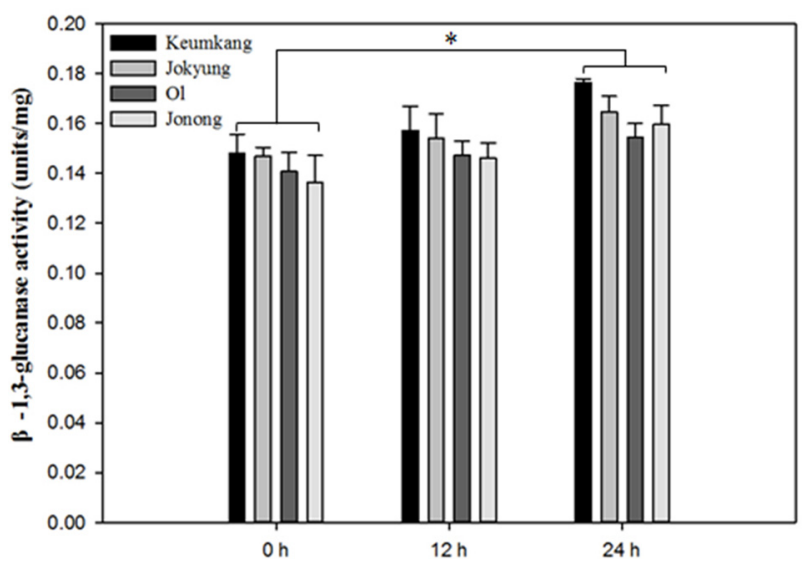

Fig. $4 \beta-1,3-$ Glucanase activity of Korean wheat varieties in response to leaf rust infection. Extracts of the first leaves of two susceptible (Keumkang, Jokyung) and two resistant (Ol, Jonong) Korean wheat varieties were sampled at 0,12 , and $24 \mathrm{~h}$ after leaf rust inoculation and then analyzed for â-1,3 glucanase activity $(* p<0.05$, Student's $t$-test)

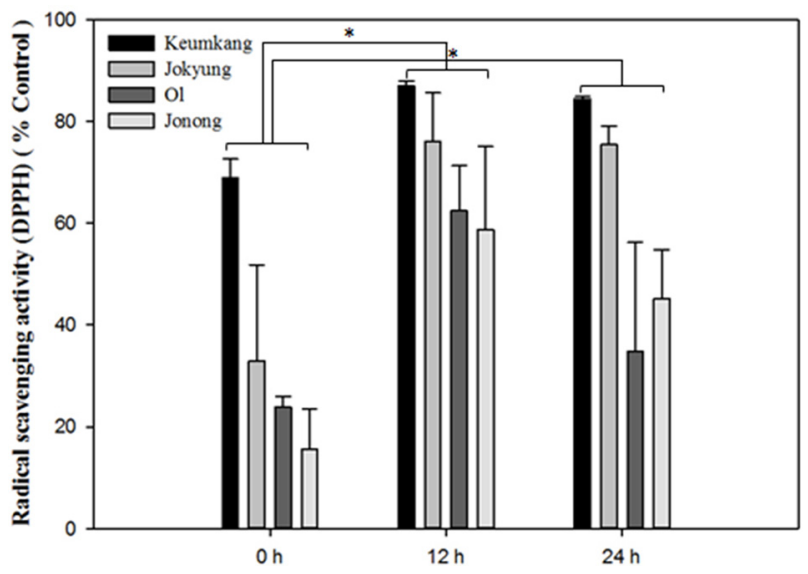

Fig. 5 Radical scavenging activity of Korean wheat varieties in response to leaf rust infection. Extracts of the first leaves of two susceptible (Keumkang, Jokyung) and two resistant (Ol, Jonong) Korean wheats were sampled at 0,12 , and $24 \mathrm{~h}$ after leaf rust inoculation and then analyzed for radical scavenging activity using DPPH $(* p<0.05$, $* * p<0.01$, Student's $t$-test)

leaf rust inoculation was examined for two susceptible and two resistant wheat cultivars. Antioxidant activity was measured by using DPPH, which quantifies radical scavenging activity [17]. The radical scavenging activity of all wheat cultivars increased at 12 and $24 \mathrm{~h}$ after inoculation. In particular, radical scavenging activity was maximal at $12 \mathrm{~h}$. Interestingly, the radical scavenging activity of $\mathrm{Ol}$ and Jonong wheat cultivars increased rapidly at $12 \mathrm{~h}$ to 61 and $73 \%$, respectively. In contrast, the radical scavenging activity of Kumkang and Jokyung wheat cultivars at $12 \mathrm{~h}$ increased to 20 and $56 \%$, respectively. These results indicate that resistant wheat cultivars might have a higher antioxidant capacity against leaf rust infection than susceptible wheat cultivars. 
Declarations The authors declare that they have no competing interests.

Acknowledgments This work was supported by the National Institute of Crop Science, Rural Development Administration, Republic of Korea [grant number PJ012496032019].

\section{References}

1. Jafarzadeh J, Bonnett D, Jannink JL, Akdemir D, Dreisigacker S, Sorrells ME (2016) Breeding Value of Primary Synthetic Wheat Genotypes for Grain Yield. PloS one 11:e0162860

2. Brown JK, Hovmoller MS (2002) Aerial dispersal of pathogens on the global and continental scales and its impact on plant disease. Science (New York, NY) 297: 537-541

3. Goutam U, Kukreja S, Yadav R, Salaria N, Thakur K, Goyal AK (2015) Recent trends and perspectives of molecular markers against fungal diseases in wheat. Front Microbiol 6: 861-861

4. Turra C, Reis EM, Barcellos AL (2014) Reaction of wheat cultivars and differential lines to Puccinia triticina races in detached leaves. Summa Phytopathologica 40: 353-357

5. Blois MS (1958) Antioxidant Determinations by the Use of a Stable Free Radical. Nature 181: 1199-1200

6. Tohge T, Nishiyama Y, Hirai MY, Yano M, Nakajima J, Awazuhara M, Inoue E, Takahashi H, Goodenowe DB, Kitayama M, Noji M, Yamazaki M, Saito K (2005) Functional genomics by integrated analysis of metabolome and transcriptome of Arabidopsis plants over-expressing an MYB transcription factor. The Plant journal : for cell and molecular biology 42: 218-235

7. Je Lee W, Young Jeong C, Lee S, Kang C-S, Lee H (2019) A comparative study on the nitrogen utilization efficiency and growth rate of domestic keumgang and chokyeong wheat vol 62. doi:10.3839/ jabc. 2019.010

8. Truong HA, Jeong CY, Lee WJ, Lee BC, Chung N, Kang C-S, Cheong Y-K, Hong S-W, Lee H (2017) Evaluation of a Rapid Method for Screening Heat Stress Tolerance Using Three Korean Wheat (Triticum aestivum L.) Cultivars. Journal of Agricultural and Food Chemistry 65: 5589-5597

9. Jung BK, Hong S-J, Park G-S, Kim M-C, Shin J-H (2018) Isolation of Burkholderia cepacia JBK9 with plant growth-promoting activity while producing pyrrolnitrin antagonistic to plant fungal diseases. Applied Biological Chemistry 61: 173-180

10. Calonge FD (1967) Chlorophyll and total nitrogen in barley rust infection. Transactions of the British Mycological Society 50: 397-IN392

11. Ni Z, Kim ED, Ha M, Lackey E, Liu J, Zhang Y, Sun Q, Chen ZJ (2009) Altered circadian rhythms regulate growth vigour in hybrids and allopolyploids. Nature 457: 327-331

12. Mauch F, Mauch-Mani B, Boller T (1988) Antifungal Hydrolases in Pea Tissue: II. Inhibition of Fungal Growth by Combinations of Chitinase and beta-1,3-Glucanase. Plant Physiol 88: 936-942

13. Balasubramanian V, Vashisht D, Cletus J, Sakthivel N (2012) Plant beta1,3-glucanases: their biological functions and transgenic expression against phytopathogenic fungi. Biotechnology letters 34: 1983-1990

14. Blättel V, Larisika M, Pfeiffer P, Nowak C, Eich A, Eckelt J, König H (2011) Beta-1,3-glucanase from Delftia tsuruhatensis strain MV01 and its potential application in vinification. Appl Environ Microbiol 77: 983990

15. Seo G, Hyun C, Choi S, Kim YM, Cho M (2019) The wound healing effect of four types of beta-glucan. Applied Biological Chemistry 62: 20

16. Park J-H, Lee H-S (2018) In vivo fungicidal properties of Diospyros kaki-isolated compound and its analogues. Applied Biological Chemistry 61: $383-388$

17. Kim J, Soh SY, Bae H, Nam S-Y (2019) Antioxidant and phenolic contents in potatoes (Solanum tuberosum L.) and micropropagated potatoes. Applied Biological Chemistry 62: 17 